\title{
Relato de experiência referente ao Estágio Supervisionado I: prática pedagógica em turmas do sétimo ano do ensino fundamental
}

\section{Experience report concerning the Supervised Internship I: pedagogical practice in classes of the seventh grade of elementary school}

Viviana Leite Pimentel ${ }^{1}$

\begin{abstract}
Resumo
Apresentamos, neste trabalho, um relato de experiência sobre a prática pedagógica realizada no decorrer da disciplina do Estágio Supervisionado I, do curso de Letras/Português do Instituto Federal do Espírito Santo - IFES. A prática foi realizada em três turmas do sétimo ano do Ensino Fundamental, na Escola Estadual de Ensino Fundamental Domingos Perim, de Venda Nova do Imigrante - ES. Cabe mencionar que a dinâmica do estágio se divide em três eixos: a observação das aulas, a coparticipação e a regência de classe, totalizando uma carga horária de 60 horas. Durante todo o percurso, foram realizadas anotações que culminaram neste relato, que tem como objetivo analisar a vivência do estágio, mais precisamente a proposta de ensino realizada nos sétimos anos, bem como refletir sobre ele. Para tanto, utilizamos como aporte teórico-metodológico os pressupostos de Pimenta e Lima (2012), Dolz, Noverraz e Schneuwly (2004), Marcuschi (2011) e Freire (2002). Concluímos que o Estágio Supervisionado é uma disciplina imprescindível no sentido de que possibilita a união entre a teoria aprendida no decorrer da graduação e a prática em sala de aula. Ademais, ao observar e refletir sobre a prática do professor regente, os estagiários começam a construir a sua identidade profissional.
\end{abstract}

Palavras-chave: Estágio Supervisionado. Ensino. Prática Pedagógica.

\begin{abstract}
In this work, we present an experience report on the pedagogical practice carried out during the Supervised Internship I discipline, of the Letters/Portuguese course of the Federal Institute of Espirito Santo - IFES. The practice was carried out in three classes of the seventh grade of the Domingos Perim State Elementary School, in Venda Nova do Imigrante - ES. It is worth mentioning that the dynamics of the internship was divided into three parts: observation of classes, co-participation, and class conducting, totaling a 60 hours workload. Throughout the internship, we took notes that resulted in this report, which aims at analyzing and reflecting on the experience of the internship, more precisely, the teaching proposal carried out in the seventh year. To that end, we used the assumptions of Pimenta and Lima (2012), Dolz, Noverraz, and Schneuwly (2004), Marcuschi (2011), and Freire (2002) as theoretical support. We conclude that the Supervised Internship is an essential discipline, once it enables the union of the course's theory and the practice in the classroom. Furthermore, by observing and reflecting on the teacher's practice, the interns begin to build their professional identity.
\end{abstract}

Keywords: Supervised Internship. Teaching. Pedagogical Practical.

\section{Introdução}

O Conselho Nacional de Educação (CNE) é o órgão que institui as Diretrizes Curriculares Nacionais para a formação do professor. Ele estabelece, por meio da Resolução CNE/CP 1, de 18 de fevereiro de 2002, que a prática do estágio deverá ser "desenvolvida com ênfase nos procedimentos de observação e reflexão, visando à atuação em situações contextualizadas, com o registro dessas

\footnotetext{
${ }^{1}$ Graduanda em Letras. Instituto Federal de Educação, Ciência e Tecnologia do Espírito Santo, Campus Venda Nova do Imigrante, Espírito Santo, Brasil. Orcid: https://orcid.org/0000-0002-5233-6599/. E-mail: viviana_vni@hotmail.com
} 
observações realizadas e a resolução de situações-problema" (BRASIL, 2002). Em consonância com 0 CNE, o Instituto Federal do Espírito Santo, conforme o Art. 2 da Resolução do Conselho Superior, de 27 de junho de 2014, menciona que

\begin{abstract}
O estágio é considerado um ato educativo escolar supervisionado, desenvolvido no ambiente do trabalho, que visa à preparação para o trabalho produtivo de educandos que estejam frequentando o ensino regular na Educação Profissional, Técnica de Nível Médio e na Educação Superior, oferecido pelo Ifes nas modalidades presencial e a distância (MINISTÉRIO DA EDUCAÇÃO, 2014, p. 01).
\end{abstract}

Diante disso, o estágio corresponde a um requisito obrigatório para a obtenção do título de licenciatura em Letras/Português. No nosso caso, também proporciona a vivência imprescindível para 0 exercício da carreira docente.

No Instituto Federal de Educação, Ciência e Tecnologia do Espírito Santo, campus Venda Nova do Imigrante, a disciplina de Estágio Supervisionado inicia-se no sexto período. Dentre a sua carga horária total, 0 aluno deve cumprir 60 horas de atividades de reflexão teórica na escola, divididas em três eixos: a observação das aulas do professor regente, a coparticipação e a regência de classe.

Este relato de experiência corresponde à prática realizada durante o componente curricular do Estágio Supervisionado I, no período de abril a junho de 2019 na Escola Estadual de Ensino Fundamental Domingos Perim, de Venda Nova do Imigrante - ES. O trabalho foi desenvolvido no turno matutino, na disciplina de Língua Portuguesa, com três turmas do sétimo ano (totalizando 80 alunos).

Para subsidiar o desenvolvimento deste relato, utilizamos como aporte teórico-metodológico os pressupostos de Pimenta e Lima (2012), Dolz, Noverraz e Schneuwly (2004) e Marcuschi (2011). Além desses teóricos, também consideramos importante conduzir nosso trabalho à luz de Paulo Freire (2002), porque seu pensamento será sempre norteador nas práticas de um bom professor.

Ressalta-se ainda a importância do Estágio Supervisionado nos cursos de licenciatura, porque dele depende, em grande medida, a qualidade da formação docente. Para a grande maioria dos discentes, é o primeiro momento em que, na posição de aprendiz de uma profissão, há o contato com a realidade escolar. Com isso em vista, é de suma relevância para os estagiários realizarem reflexões sobre a experiência do estágio, buscando unir a teoria aprendida na graduação à prática em sala de aula.

\title{
20 estágio supervisionado
}

Entendemos que o estágio supervisionado corresponde a uma vivência rica e importante para a formação de qualidade dos futuros professores. No mesmo caminho, Pimenta e Lima (2012, p. 123) 
argumentam que "o estágio é o eixo central na formação de professores, pois é através dele que o profissional conhece os aspectos indispensáveis para a formação da construção da identidade e dos saberes do dia-a-dia". Dessa maneira, ele proporciona o conhecimento da realidade da escola, tornandose uma atividade fundamental de reflexão sobre as práticas pedagógicas, como podemos observar por meio do excerto:

Ao transitar da universidade para a escola e desta para a universidade, os estagiários podem tecer uma rede de relações, conhecimentos e aprendizagens, não com o objetivo de copiar, de criticar apenas os modelos, mas no sentido de compreender a realidade e ultrapassá-la (PIMENTA; LIMA, 2012, p. 111).

Entretanto, as autoras evidenciam uma dificuldade do estágio que é o distanciamento entre teoria e prática, conforme explanam no trecho "o reducionismo dos estágios às perspectivas da prática instrumental e do criticismo expõe os problemas na formação profissional docente. A dissociação entre teoria e prática aí presente resulta em um empobrecimento das práticas nas escolas" (PIMENTA; LIMA, 2012, p. 41). Para as autoras, em grande medida, o estágio fica reduzido à prática instrumental, dissociado da teoria. Contudo, é necessário adotar uma postura diferente, de reflexão da realidade escolar, unindo teoria e prática. Nesse caminho, as autoras argumentam que,

[...] o papel das teorias é iluminar e oferecer instrumentos e esquemas para a análise e investigação que permitam questionar as práticas institucionalizadas e as ações dos sujeitos e, ao mesmo tempo, colocar elas próprias em questionamento, uma vez que as teorias são explicações sempre provisórias da realidade (PIMENTA; LIMA, 2012, p. 43).

Salientamos, por fim, que o graduando experimenta um ambiente propício de enriquecimento profissional, acadêmico e até mesmo pessoal durante o estágio. Isso acontece pois ele reflete sobre a nova realidade que está vivenciando, bem como testa diferentes maneiras de ensinar, sem a responsabilidade de ser o professor regente.

\section{Descrição da experiência}

Um dos requisitos da disciplina de Estágio Supervisionado I, da graduação em Letras/Português do Instituto Federal de Educação, Ciência e Tecnologia do Espírito Santo - Ifes, campus Venda Nova do Imigrante, é o cumprimento de sessenta horas de atividades de reflexão teórica, na escola, divididas em três eixos: observação (ou revisão) e análise da realidade; atividades de coparticipação; e docência compartilhada, em uma escola da região que oferte o ensino Fundamental II. 
No princípio, apenas fizemos a observação das aulas do professor tutor. Em seguida, fomos convidados por ele a desempenhar atividades de coparticipação. Dentre elas, destacamos as seguintes: auxiliar os alunos, dar visto no caderno, corrigir avaliações e mediar leitura.

Em relação ao visto no caderno, adotamos a estratégia do carimbo, utilizada pela professora orientadora, Selma Lucia Pereira, em sua prática docente. Pensando na faixa etária - adolescentes utilizamos dois carimbos com figuras do tipo emoji, análogas aos emojis da rede social Facebook. Pela reação dos alunos, a estratégia foi bem-sucedida, pois eles passaram a realizar as tarefas. Consideramos importante, porém, fazer a ressalva de que é necessário ler as respostas das atividades realizadas pelos alunos, porque em alguns casos, no afã de receber o carimbo, a atenção dedicada às tarefas pode ficar em segundo plano, o que não foi nosso objetivo.

Também foi realizada a correção das avaliações de Língua Portuguesa, em que constatamos, por meio dos resultados, que muitos alunos erraram questões simples, como destacar o verbo num texto. Além disso, havia uma questão que exigia uma resposta pessoal e a grande maioria dos alunos errou ou copiou do texto, ipsis litteris. Apreendemos que, em muitos casos, os alunos aparentemente não leem as questões ou simplesmente decodificam, mas não compreendem. Assim, não conseguem elaborar respostas satisfatórias.

Depreendemos que uma quantidade bastante significativa desses alunos não consegue fazer inferências, nem mesmo manter o foco para ler e interpretar os enunciados, acarretando, dessa forma, em respostas equivocadas. Sobre isso, Marcuschi (2011) afirma que "[...] a compreensão não é um simples ato de identificação de informações, mas uma construção de sentidos com base em atividades inferenciais" (MARCUSCHI, 2011, p. 90). Com base nisso, percebemos que a maioria dos alunos não chegam a obter a compreensão dos conteúdos estudados, o que é bastante preocupante.

A fim de evidenciar alguns dados e com o intuito de facilitar a visualização de como foi 0 rendimento das turmas na avaliação, elaboramos os gráficos abaixo: 


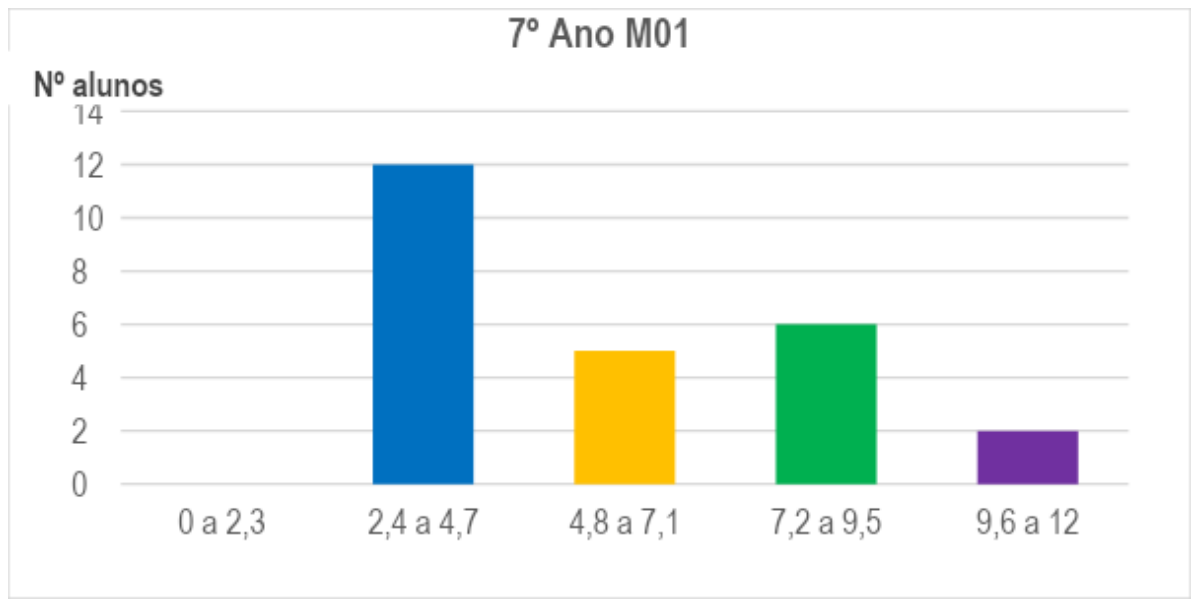

Gráfico 1. Desempenho do $7^{\circ}$ ano M01 na Avaliação de Língua Portuguesa Fonte: Elaborado pela autora

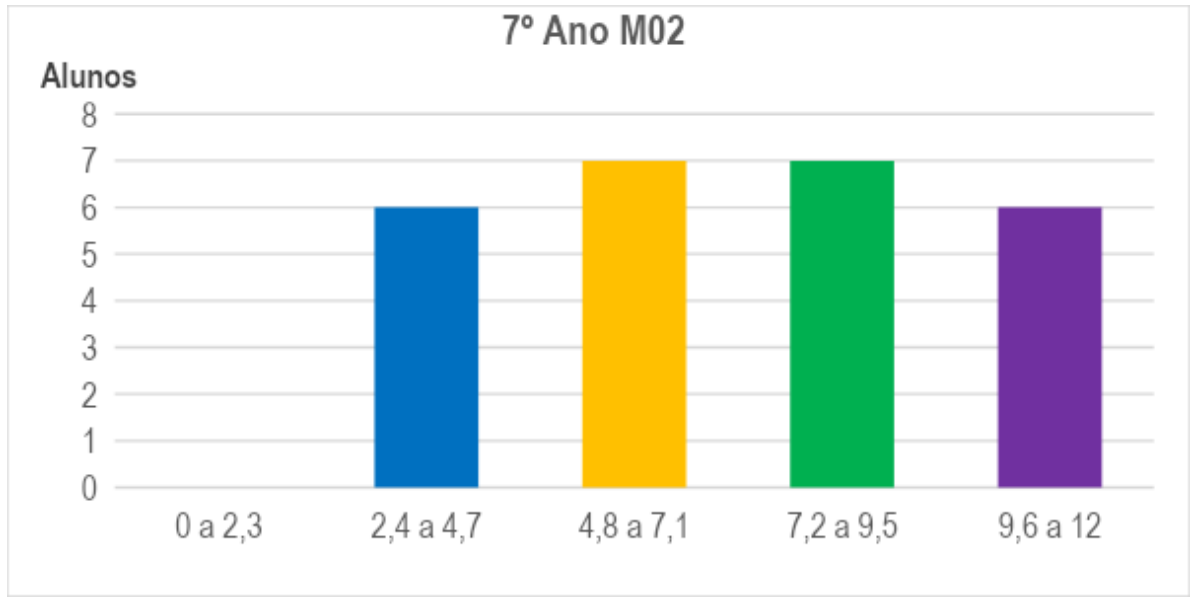

Gráfico 2. Desempenho do $7^{\circ}$ ano M02 na Avaliação de Língua Portuguesa.

Fonte: Elaborado pela autora

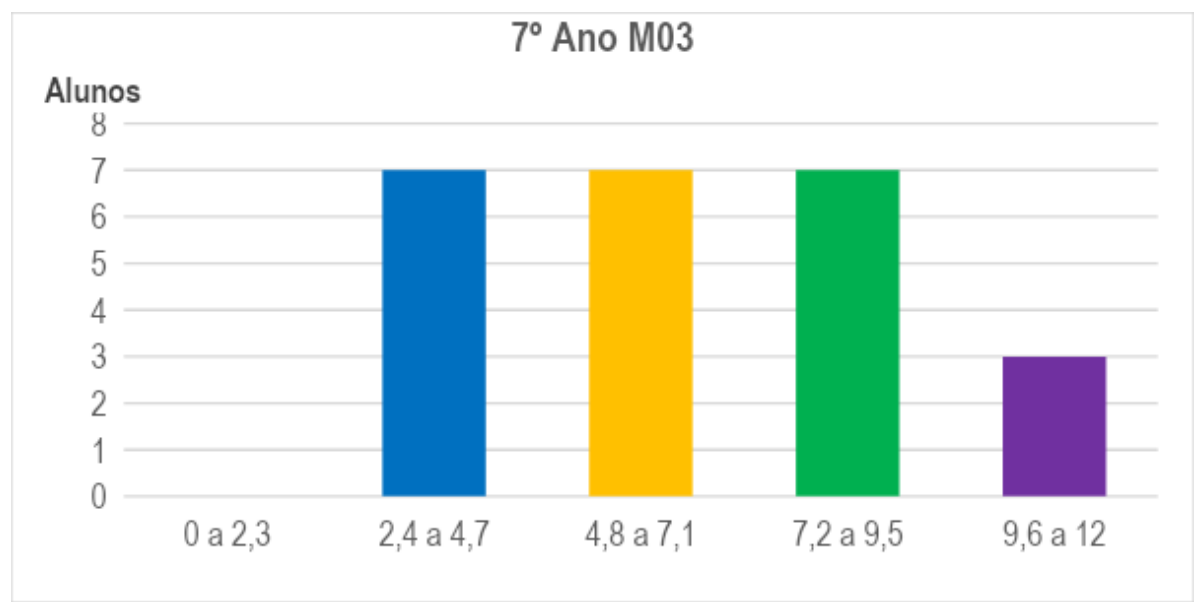

Gráfico 3. Desempenho do $7^{\circ}$ ano M03 na Avaliação de Língua Portuguesa.

Fonte: Elaborado pela autora

LínguaTec, Instituto Federal de Educação, Ciência e Tecnologia do Rio Grande do Sul, Bento Gonçalves 
Ao todo, 75 alunos realizaram a avaliação, sendo 25 alunos no $7^{\circ} \mathrm{M} 01,26$ alunos no $7^{\circ} \mathrm{M} 02$, e 24 alunos no $7^{\circ} \mathrm{M} 03$. Por meio dos gráficos, podemos evidenciar algumas situações: em relação ao $7^{\circ}$ ano M01, observa-se que mais de 50\% dos alunos tiraram uma nota inferior a $60 \%$, isto é, mais da metade da turma tirou nota abaixo da média. A turma, de fato, é a mais agitada dentre as 03 turmas, e também é a que mais sofre pelo barulho advindo das aulas de educação física, devido à proximidade da sala à quadra de esportes. Provavelmente esses fatores influenciaram no rendimento dos alunos. As outras duas turmas, por sua vez, conseguiram obter um resultado mais satisfatório, pois muitos tiraram notas superiores aos $60 \%$. No $7^{\circ} \mathrm{M} 02$, metade da turma não atingiu a média. № $7^{\circ} \mathrm{M} 03$, mais da metade também não atingiu a média.

Evidenciamos, ainda, que as turmas estão em níveis diferentes de aprendizagem, visto que alguns alunos conseguiram alcançar bons resultados, outros estão na média e outros não conseguiram resultados satisfatórios. Talvez coubesse propor atividades de nivelamento para que haja maior equilíbrio em relação à aprendizagem desses alunos. Ademais, cabe salientar que apenas uma parcela pequena de alunos conseguiu tirar notas acima de 10,8, isto é, mais de $80 \%$ do valor total da prova. Além disso, nenhum aluno, em nenhuma turma, acertou $100 \%$ das questões.

Evidentemente, não se deve considerar as notas como um fim em si mesmas. Muitos outros fatores afetam no rendimento dos alunos. Todavia, os resultados obtidos podem direcionar as práticas do professor, visando uma aprendizagem mais satisfatória.

Houve, também, a oportunidade de realizar a mediação de leitura do livro Zoom, de Istvan Banyai. Essa obra não possui texto (palavras), só imagens. Cada página é uma imagem e, pouco a pouco, essas imagens vão ampliando como se estivesse reduzindo o zoom. Foi uma atividade interessante, os alunos foram bastante participativos e, aparentemente, gostaram do livro. Consideramos a atividade importante para explorar o conhecimento de mundo dos alunos e também para trabalhar a oralidade.

Ressaltamos que a mediação não é tarefa simples. Ela requer preparo por parte do professor e conhecimento acerca da obra escolhida, mas não só isso. É necessário ter um pouco de expertise e conhecimento de mundo para que se consiga "pegar alguns ganchos" para desenvolver assuntos diversos.

Acreditamos que a leitura em sala de aula é imprescindível e que uma boa mediação faz toda a diferença na formação do aluno. Posto isto, devemos nos preocupar com a nossa responsabilidade nesse processo e consideramos importante participar de formações ou cursos em mediação de leitura. 
Como mencionado anteriormente, uma parte do estágio é destinada à regência de classe. Por isso, a sugestão do professor tutor foi a de que trabalhássemos a obra 0 pequeno príncipe, de Antoine de Saint-Exupéry, devido às temáticas abordadas no livro, que são interessantes para a formação humanística do aluno, como a importância da amizade, as reservas morais etc.

Nesse sentido, elaboramos uma Sequência Didática (SD) a partir dos pressupostos de Dolz, Noverraz e Schneuwly (2004), cuja definição é a de que se trata de "um conjunto de atividades escolares organizadas, de maneira sistemática, em torno de um gênero textual oral ou escrito" (DOLZ, NOVERRAZ E SCHNEUWLY, 2004, p. 82). Ainda na perspectiva desses teóricos, a Sequência Didática tem como finalidade "ajudar o aluno a dominar melhor um gênero, permitindo, assim, escrever ou falar de maneira mais adequada numa dada situação de comunicação" (DOLZ, NOVERRAZ E SCHNEUWLY, 2004, p. 97). Posto isto, salientamos a importância do trabalho tomando como base a Sequência Didática.

Considerando os pressupostos acima, trabalhamos com o gênero textual comentário, juntamente com a obra 0 pequeno príncipe. A escolha do gênero justifica-se, pois ele faz parte do cotidiano do aluno, tanto oralmente, quanto escrito (em redes sociais, por exemplo). Além disso, por meio desse gênero discursivo, o aluno demonstra seu ponto de vista, posiciona-se, argumenta.

Acreditamos que incentivar a argumentação dos estudantes contribui para o desenvolvimento do pensamento crítico deles, habilidade essa essencial para o exercício da cidadania. Para além disso, constatamos que, ultimamente, têm crescido de forma assustadora os comentários em redes sociais nos quais as pessoas utilizam um discurso de ódio e intolerância. Tais práticas são extremamente nocivas para a vida em sociedade. Dessa maneira, trabalhar com o gênero comentário, além de contribuir para a construção de conhecimentos acerca do gênero, possibilita orientar para o respeito e tolerância para com os demais ao expor opiniões e ao argumentar sobre questões diversas.

Como não havia como conseguir cópia do livro para todos os alunos, nem tempo hábil para a leitura, optamos pela exibição do filme 0 pequeno príncipe. Posteriormente, propomos a leitura de pequenos trechos da obra em sala de aula.

Os alunos assistiram ao filme na Casa da Cultura - espaço que conta com uma sala de vídeo ampla e confortável, em Venda Nova do Imigrante, porque esse espaço tem capacidade para comportar todos os alunos. Além disso, eles puderam sair da rotina de sala de aula, o que acreditamos ser importante para eles. Consideramos importante mencionar ainda o apoio que a diretora e a pedagoga nos deram ao proporcionar esse "passeio" com os estudantes.

Após a exibição do filme, discutimos sobre ele. Num primeiro momento, apresentamos a proposta de se trabalhar o gênero textual comentário a partir da obra. Explanamos sobre o conceito do 
gênero e apresentamos suas características. Após isso,, entregamos uma folha em branco para cada aluno e solicitamos que eles produzissem um comentário escrito sobre suas percepções acerca do filme. Além disso, sugerimos que também fizessem ilustrações sobre a cena que mais gostaram. Cabe mencionar, sobre esse ponto, que os alunos, de fato, produziram os textos, alguns com mais facilidade, outros com menos, mas não deixaram de produzir.

Por fim, confeccionaram um mural que tinha o layout de uma página da rede social Facebook, onde foram colados os comentários e as ilustrações produzidos por eles. Depois de pronta a atividade, cada aluno recebeu um emoji para curtir o trabalho que mais gostou. Esse momento de interação foi muito proveitoso, os alunos gostaram bastante.

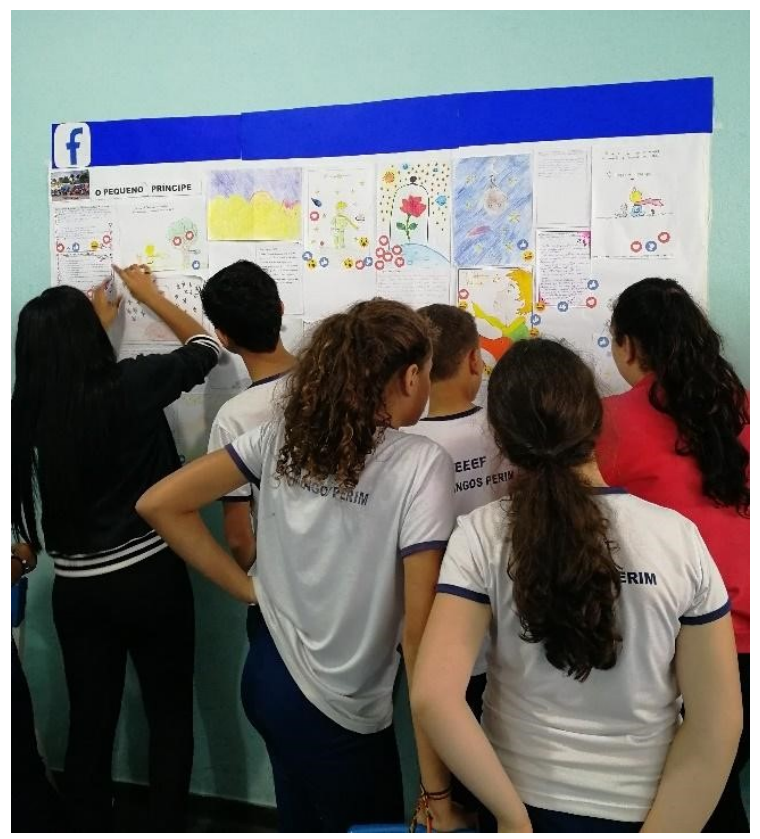

Figura 1. Confecção do mural de comentários e ilustrações sobre 0 pequeno príncipe, no $7^{\circ} \mathrm{M} 02$

Fonte: Registro feito pela autora

\section{Reflexões sobre a experiência do estágio}

A reflexão, de fato, permeia a vivência do estágio, desde a observação das práticas do professor regente até a aplicação da proposta de aula. Nessa perspectiva, corroboramos o pensamento de Paulo Freire (2002, p. 43-44) que nos diz que "na formação permanente dos professores, o momento fundamental é o da reflexão crítica sobre a prática. É pensando criticamente a prática de hoje ou de ontem que se pode melhorar a próxima prática". Acreditamos que o momento é oportuno para aproveitar as práticas boas do professor tutor e pensar em maneiras de reformular as que não são tão boas. Nesse sentido, consideramos indispensável a oportunidade de conhecer a realidade da sala de aula e das práticas do professor regente, para, a partir disso, formularmos os nossos modelos de aula. 
A reflexão também possibilita fazer algumas indagações sobre como deve ser a prática ou as práticas docentes mais adequadas para evitar o fracasso escolar. Acreditamos que esse seja o grande desafio da docência. Para os alunos, ao que parece, qualquer coisa é mais interessante do que estudar. Algumas vezes eles até estão em silêncio, mas isso não significa que estejam prestando atenção na aula. Já para os professores, alguns fatores revelam os desafios enfrentados: o mundo atual, dinâmico e instantâneo, ocasionado pelo advento da internet; as famílias cada vez mais desestruturadas e ausentes; o sucateamento da educação; dentre outros.

Tudo influi no processo de aprendizagem do aluno e contribui para que ele tenha dificuldades de concentração e foco, além de não adquirir consciência da importância dos estudos e da disciplina, necessários para um bom desempenho escolar. Nesse cenário, tem ficado a cargo da escola a tentativa de dirimir os problemas da formação (acadêmica e humanística) dos jovens, papel injusto, pois requer responsabilidades que deveriam ser de todos.

No decorrer das atividades propostas na Sequência Didática, os alunos vivenciaram diferentes situações: saíram da rotina para assistir ao filme, tiveram momentos de interação na área de lazer, fizeram leituras, produziram textos, ilustrações e o mural. De uma forma geral, os alunos foram bastante participativos e disseram ter gostado das atividades. Sobre a produção textual, evidenciamos que muitos alunos têm dificuldade de escrever e também de fazer inferências. Nesse sentido, caberia propor mais atividades e leituras que os levem à reflexão e que desenvolvam o pensamento crítico. Esperamos, por fim, que as atividades propostas tenham contribuído para a formação humanística desses alunos.

\section{Considerações finais}

Diante do exposto, consideramos importante ratificar que a vivência do estágio é uma experiência imprescindível, como anteriormente citado, pois permite aos estagiários conhecer a rotina da escola, a realidade dos professores e dos alunos, as práticas docentes, entre outros. A partir disso, podemos refletir sobre os métodos utilizados e aperfeiçoar as práticas pedagógicas futuras.

Salientamos que é por meio da reflexão que podemos repensar a prática. Consequentemente, começamos a criar nossa identidade como docente, isto é, passamos a elaborar o nosso próprio modo de ser e de fazer.

O estágio também é um momento oportuno para relacionar os conteúdos estudados na graduação com a prática vivenciada na escola, sob a supervisão do orientador. Com isso, a construção 
de conhecimento do graduando torna-se muito mais consistente, já que houve a união da teoria com a prática.

Por fim, cabe mencionar que também é uma experiência difícil e exigente, porque requer dedicação, planejamento e associação dos conteúdos teóricos às práticas. Além disso, percebemos que os desafios da profissão são inúmeros, entretanto, esperamos, por meio do trabalho e do estudo, colher bons frutos na carreira docente.

\section{Referências}

BRASIL. Conselho Nacional de Educação. Define as Diretrizes Curriculares Nacionais para a formação inicial em nível superior (cursos de licenciatura, cursos de formação pedagógica para graduados e cursos de segunda licenciatura) e para a formação continuada. Resolução CNE/CP n. 01, de 18 de fevereiro de 2002. Brasília, Diário Oficial [da] República Federativa do Brasil, 18 de fevereiro de 2002. Disponível em: http://portal.mec.gov.br/seesp/arquivos/pdf/res1_2.pdf.

DOLZ, J.; NOVERRAZ, M.; SCHNEUWLY, B. Sequências didáticas para o oral e a escrita: apresentação de um procedimento. In: DOLZ, J.; SCHNEUWLY, B. e colaboradores. Gêneros orais e escritos na escola. Trad. e Org. de R. R. e G. S. C. Campinas, SP: Mercado das Letras, 2004.

FREIRE, P. Pedagogia da Autonomia: Saberes necessários à prática educativa. Rio de Janeiro: Paz e Terra, 2002.

MARCUSCHI, L. A. Compreensão textual como trabalho criativo. In: Universidade Estadual Paulista. Prograd. Caderno de formação: formação de professores didática geral. São Paulo: Cultura Acadêmica, v. 11. 2011.

MINISTÉRIO DA EDUCAÇÃO. Instituto Federal de Educação, Ciência e Tecnologia do Espírito Santo. Conselho Superior. Resolução No 28 de 27 de junho de 2014. Aprova a regulamentação dos estágios dos alunos da Educação Profissional Técnica de Nível Médio e da Educação Superior do Ifes. Vitória, ES, 2014.

PIMENTA, S. G.; LIMA, M. S. L. Estágio e Docência. 7ª ed. São Paulo: Cortez Editora, 2012.

Data de submissão: 02/09/2020. Data de aprovação: 22/10/2020. 